\title{
Modelos de acumulación de capital y estructura laboral en El Salvador. $1900-2007$
}

RESUMEN: En este trabajo se pretende mostrar cómo las características de la fuerza de trabajo se han ido adaptando a los distintos modelos de acumulación de capital que han existido en El Salvador desde el año de 1900 hasta la actualidad. La investigación y la exposición se realizó atendiendo a los tres modelos económicos identificados en El Salvador: modelo agroexportador basado en el café (1900-1944), modelo agroexportador con impulso a la industria manufacturera (1948-1979) y modelo terciario-maquilero (1989-2007). Una buena parte del instrumental teórico de este trabajo proviene del pensamiento del economista Aquiles Montoya.

ABSTRACT: This paper is intended to demostrate how the features of the labor force have been adapting themselves to the different models of accumulation of capital in El Salvador since 1900. The research adressed the three economic models that were identified in El Salvador, i.e., the agro-export model based on the coffee crop (1900-1944), the agro-export model that fostered the manufacturing industry (1948-1979) and the maquila-tertiary model (1989-2007). A very important part of the theoretical instrumental of this paper comes from the contribution of the late economist Aquiles Montoya.

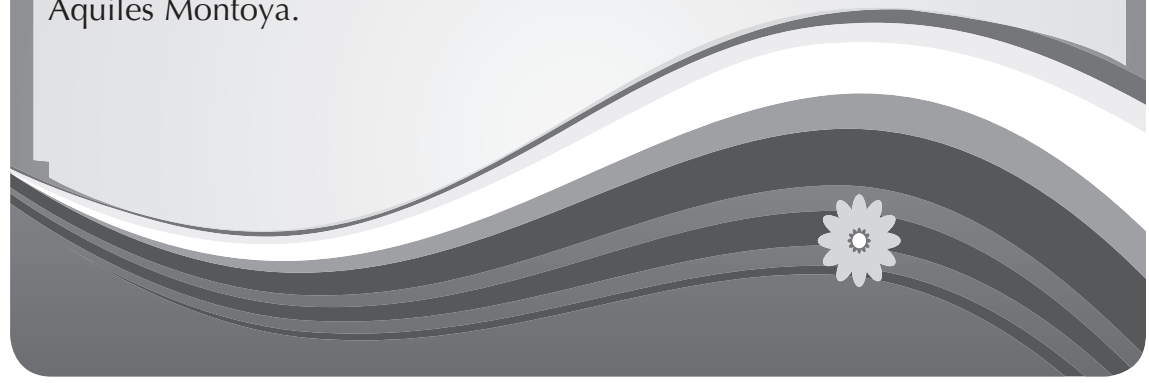




\section{Introducción}

E Informe sobre Desarrollo Humano El Salvador 2007-2008, titulado El empleo en uno de los pueblos más trabajadores del mundo, pone de manifiesto algunos de los problemas actuales del mercado laboral salvadoreño, entre ellos el subempleo, los salarios reales bajos y la extensión del sector informal urbano.

Según este informe, el subempleo es la manera en que se ocupa el $43 \%$ de la población económicamente activa del país. Esto lo convierte en el problema principal del mercado laboral salvadoreño, por encima incluso del desempleo "un lujo que, en el país, pocos pueden darse" (PNUD, 2008:5). Además, Ilama la atención la magnitud del llamado sector informal urbano. Muchas de las personas ahí empleadas tienen que lidiar con ingresos menores al salario mínimo legal, falta de seguridad social e inseguridad en sus ingresos.

La disparidad de oportunidades de empleo por zona geográfica es otro de los problemas puesto en evidencia en el informe. La mayoría de empleos considerados decentes se han concentrado en el área metropolitana de San Salvador. Este empleo decente depende de muchas cosas, entre ellas la estabilidad laboral, el acceso a seguridad social y un salario decente. Lamentablemente, la mayoría de personas empleadas en El Salvador, no cuenta con ninguna de estas ventajas.

En cuanto a la educación de la fuerza de trabajo, el informe destaca que, aunque la población cuenta con un nivel educativo más alto, las oportunidades laborales no han crecido. Los niveles de desempleo son mayores a medida que el nivel educativo sube, a tal punto que para 2006 el $30 \%$ del total de desempleados eran personas con niveles de bachillerato y educación superior (PNUD, 2008).

Los salarios, por su parte, muestran un comportamiento que contradice a la teoría económica ortodoxa y al discurso oficial, pues, a pesar de que la productividad del trabajo ha aumentado, los salarios mínimos y promedios reales no han hecho otro tanto. De hecho, el propio nivel de los salarios reales es lo más preocupante, ya que la mayoría de la población no devenga un salario considerado decente, entendido como aquel que permite satisfacer todas las necesidades de la persona trabajadora y su familia.

Ahora bien, muchas veces estos problemas son atribuidos a la coyuntura mundial, a la implementación de determinadas políticas económicas de gobiernos recientes o a la manera en que se ha organizado el modelo económico nacional 
actual. Sin embargo, es necesario considerar que las características de la fuerza de trabajo de un país, tienen antecedentes históricos que ayudan a explicarla. Hay que reconocer que estas son fruto de complejos procesos históricos.

Así pues, se vuelve necesario el reconocimiento de que el modelo económico se objetiva sobre una base social preexistente que ha sido afectada por modelos económicos anteriores. Y no sólo es necesario reconocer este hecho, sino además analizar la manera en que modelo y estructura laboral se vinculan, para así poder dar paso a respuestas más certeras a los problemas laborales actuales.
En este sentido, hacer una revisión histórica de la estructura laboral y su vinculación con cambios en los modelos económicos en El Salvador, puede ser útil en la medida que ofrecería una visión más amplia sobre el surgimiento y la consolidación de algunas de las principales características de fuerza de trabajo salvadoreña.

Por tanto, el objetivo principal de este trabajo es mostrar cómo las características de la fuerza de trabajo se han ido adaptando a los distintos modelos de acumulación de capital que han existido en $\mathrm{El}$ Salvador desde el año de 1900 hasta la actualidad.

\section{Metodología}

La metodología usada para realizar este trabajo se basó principalmente en la investigación bibliográfica y estadística. Además se construyó un marco de referencia, en el cual se desarrollaron las categorías utilizadas y se vinculó, a nivel teórico, los modelos de acumulación con la estructura laboral.

La investigación y la exposición se realizó atendiendo a los tres modelos económicos identificados en El Salvador: modelo agro-exportador basado en el café (1900-1944), modelo agro-exportador con impulso a la industria manufacturera (19481979) y modelo terciario-maquilero (1989-2007). Asimismo, se hizo una breve reseña del período de formación del capitalismo en El Salvador (segunda mitad del siglo XIX), y se omitieron los años del conflicto bélico en El Salvador (1980-1988), por considerarse un período de transición al modelo económico vigente.

Las limitaciones enfrentadas para el desarrollo de la investigación fueron la imposibilidad de encontrar datos estadísticos homogéneos entre periodos. En muchos casos, las fuentes estadísticas o bibliográficas no existían o se habían perdido de los registros nacionales. Además, la amplitud del período histórico estudiado dificultó ahondar mucho en detalles. 


\subsection{Marco de referencia}

La estructura laboral de un país puede ser entendida como el conjunto de elementos que caracterizan cualitativa y cuantitativamente el empleo de las fuerzas productivas humanas (Población Económicamente Activa, PEA). Este conjunto de elementos, cuantitativos y cualitativos, son las características que se relacionan con la cualificación, los sueldos y salarios, las condiciones de empleo y los sectores de la producción en que la PEA se ocupa.

Esto nos remite a los ámbitos de la producción y de la circulación, al interior de los cuales se encuentran sectores productivos que pueden ser catalogados como ejes de acumulación. Así, de manera general, se observa que cualquier actividad económica susceptible de producir o realizar plusvalía puede convertirse, desde la óptica capitalista, en un eje de acumulación.

Ahora bien, para que un sector productivo de la economía pase a ser considerado como "eje de acumulación", es necesario que la actividad específica que se desarrolla en este, se convierta en el motor de la dinámica económica capitalista.

Estos sectores son los que influyen más en la estructura laboral, en primer lugar porque condicionan el empleo de las fuerzas producti- vas humanas $y$, en segundo lugar, en tanto que son los motores de la dinámica capitalista para una Formación Económica Social (FES). Esta última, según Montoya (1998: 13), "sería una realidad estructurada y cambiante en la cual existe un modo de producción determinante que le asigna su carácter y naturaleza a la FES y otras formas económicas, ideológicas y políticas que no son propias del Modo de Producción, (MP), que especifica a la FES, las cuales, pueden o no estar subordinadas al MP determinante".

Por otro lado, el eje de acumulación forma parte de un modelo económico. Este, al ser la modalidad particular que reviste a nivel de FES un determinado modo de producción (Montoya, 1998), se presenta como una realidad más compleja, que incluye otros aspectos de la vida social, entre ellos aspectos políticos, jurídicos, culturales, etc. $Y$ es justamente mediante la inclusión de estos aspectos, distintos de lo económico, que el modelo económico se constituye en un elemento explicativo más amplio de la estructura laboral.

El modelo económico al adquirir realidad en una FES determinada es afectado por las particularidades que esta posee. Estas se han conformado en la medida que la FES es afectada por modelos económicos anteriores, por las relaciones que 
mantiene con otros países y por las características propias de las FES subdesarrolladas, tales como la dependencia e importancia relativa de las formas económicas no capitalistas.

Esta dependencia de las FES subdesarrolladas se manifiesta en los ámbitos económicos, sociales, culturales y políticos. Y, en cuanto a la relevancia de las formas económicas no capitalistas, se destaca su importancia en términos de ocupación y de producción (aunque muchas veces esto no se ve reflejado en las cuentas oficiales)

Así pues, la estructura laboral, es influida en forma inmediata por el eje de acumulación, y de manera mediata por las particularidades de cada FES y las relaciones que estas mantiene con el resto del mundo. Esto impide que la estructura laboral sea una realidad inmutable; por el contrario, sus cambios se corresponden con los cambios del modelo económico y de las situaciones que afectan a este.

\subsection{Del añil al café: formación de una estructura laboral capitalista}

Para los inicios del siglo XX, El Salvador ya era un país con un pasado eminentemente agroexportador. La producción de café para aquel entonces se había convertido en el principal cultivo de exportación del país, desplazando al añil, que por varios siglos había sido la principal fuente de riqueza nacional.

La transición del añil al café en la economía salvadoreña fue gradual y relativamente lenta. En parte, esta transición se vio motivada por el decaimiento de la demanda de añil ocasionada, entre otras cosas, por el surgimiento de productos químicos sustitutos del colorante natural (isotina en 1879 y anilina en 1882).

Asimismo, el gobierno proporcionó algunos incentivos para que los productores nacionales cambiaran sus cultivos habituales por cultivos considerados de "alto valor comercial", entre ellos el café. Por otra parte, los precios internacionales del café fueron en aumento y sus costos de transporte disminuyeron, especialmente luego de la inauguración de la Panamá Railroad en 1855

Las exportaciones de añil disminuyeron desde el año 1872, y al mismo tiempo las exportaciones de café experimentaron un crecimiento muy acelerado, tanto es así que para el año 1892 estas representaban treinta y seis veces el valor de las exportaciones del añil.

Ahora bien, el cultivo de café requería de ciertas condiciones que no habían sido necesarias para el cultivo de añil: las extensiones para el café debían ser grandes, en zonas altas, con los suelos ácidos y 
delgados; la inversión inicial debía ser considerable, y la fuerza de trabajo necesaria debía ser abundante y temporal.

Estas exigencias particulares se tradujeron en importantes transformaciones dentro de la economía. Una de ellas fue el cambio en la geografía económica de la nación, ya que mientras la producción de añil se concentraba en la zona oriental, los requerimientos de los suelos para el cultivo del café hacían que las actividades económicas se concentraran en la zona central y occidental.

Otro cambio muy importante dentro de la estructura económica que merece especial atención fue la privatización de tierras comunales y ejidales, ocurrida principalmente en aquellos departamentos del occidente del país. Los gobiernos liberales en los años 1878 y 1879, concluyeron que el desarrollo de la agricultura comercial, en especial aquella dedicada al café, se lograría únicamente si la tierra cultivable estaba en manos de individuos como propiedad privada. Con base en ello se impulsaron las conocidas "reformas liberales", en las que se decreta el primer instrumento legal de abolición de tierras comunales el 26 de febrero de 1881 .

Para Lindo (2002), la abolición de este tipo de propiedad, a través del impulso de las reformas liberales, respondió en mayor medida a la creciente demanda de productos agrícolas del exterior que convirtió a la tierra en un bien más codiciado, así como también a "los cambios en la balanza de poder entre las comunidades indígenas y los terratenientes ladinos interesados en producir para los mercados internacionales", (Lindo: 223,2003)

Posteriormente en los años 1882, 1897 y 1912, se crearon más leyes que promovieron la propiedad privada dentro de la nueva economía agrícola salvadoreña. Entre esas leyes se encontraba la ley de "Jornaleros y creación de jueces agrarios" (1881), conocida popularmente como "leyes contra la vagancia", en la que se establecía la obligatoriedad del trabajo en función de las necesidades de fuerza de trabajo de los cafetaleros.

Si bien es cierto la escasez de mano de obra era una característica permanente en la economía salvadoreña del siglo XIX, al expropiar muchos trabajadores y "liberarlos" de medios de vida, se estaba creando un excedente de fuerza de trabajo disponible para el sector cafetalero. Esto, sumado con la creación de leyes en contra de la "vagancia", hace que una parte de la población, ya sea voluntaria o forzosamente, se ocupara en el sector cafetalero.

De esta manera, el capitalismo se instaura en el sector cafetalero y es a través de este que muchos trabajadores agrícolas de la época 
se convirtieron en trabajadores asalariados temporales. Sin embargo, no toda la población salvadoreña tenía cabida en el sector capitalista de la economía. Por ello, las formas económicas no capitalistas, que en su mayoría era la agricultura de subsistencia, no solamente fueron toleradas por el nuevo sistema económico, sino que se convirtieron en "cómplices" del desarrollo del capitalismo en El Salvador. Con este proceso, La estructura laboral sufre, probablemente, la transformación más importante durante la segunda mitad del siglo XIX gracias al surgimiento de las relaciones sociales de producción capitalistas.

Así, a finales del siglo XIX, la economía salvadoreña presentaba rasgos característicos de una economía capitalista agro-exportadora subdesarrollada y en ese sentido, la estructura laboral se correspondería a ello.

\subsection{0-1944: Modelo agroexportador basado en el café}

\subsubsection{Contextualización}

En el ámbito internacional, ocurrieron algunos acontecimientos muy importantes, que repercutieron en la vida política, social y económica del país, entre ellas: la crisis financiera (1914-1922), la Primera Guerra Mundial (1914-1918), el triunfo de la revolución rusa (1917), la crisis capitalista mundial de los años treinta, la Segunda Guerra Mundial (1939-1945), y dentro de la región, la revolución mexicana (1910-1917) y el antiimperialismo del pueblo de Nicaragua liderado por Augusto César Sandino.

De todos los sucesos anteriores el que impactó más fuerte en El Salvador fue la crisis capitalista mundial de los años treinta. Con la crisis, los precios internacionales del café disminuyeron de manera acelerada, ya para 1930 el precio medio por quintal había disminuido un $44.6 \%$ con respecto a 1929 .

La crisis afectó sobre todo a los pequeños y medianos productores de café, quienes difícilmente lograban recuperar los costos de producción; y a las clases populares, cuyas condiciones de vida empeoraron considerablemente, especialmente en el área rural donde el desempleo aumentó y los jornales de los campesinos, que antes de la crisis oscilaban alrededor de los 50 centavos diarios, bajaron a menos de la mitad (Cáceres, 1986).

Las pésimas condiciones de vida de la población, junto con la gran agitación sociopolítica que vivía el país, desembocaron en "la conocida y bastante publicitada insurrección campesina de enero de 1932, la cual es abortada a base de una represión cruenta inédita en el país, que deja un saldo no exactamente calculado de entre 15 a 30 mil personas asesinadas, en su 
mayoría campesinos" (Castro, 1979:

2; Citado en Cáceres, 1986: 100).

\subsubsection{Modelo económico}

\subsubsection{Eje de acumulación: cultivo y exportación de café}

Al Ilegar la primera década del siglo XX, las exportaciones de materias primas y alimentos eran la fuente más importante de riqueza en la nación, sino es que la única, y estas dependían enormemente de los precios internacionales de esos productos, en especial del precio del café. Esto permite ubicar a El Salvador de este período como un país agro-exportador, en el que el sector cafetalero es el más dinámico de toda la economía; el que cumple el papel de eje de acumulación en el modelo primario exportador salvadoreño.

\section{Cuadro 1}

\section{Composición porcentual de las exportaciones para el período 1901-1927}

\begin{tabular}{ccrrrr}
\hline Año & \multicolumn{1}{c}{ Añil } & Azúcar & \multicolumn{1}{c}{ Bálsamo } & \multicolumn{1}{c}{ Café } & \multicolumn{1}{c}{ Otros } \\
\hline $\mathbf{1 9 0 1}$ & $11.10 \%$ & $4.00 \%$ & $2.00 \%$ & $76.00 \%$ & $6.90 \%$ \\
$\mathbf{1 9 1 0}$ & $1.90 \%$ & $3.90 \%$ & $0.70 \%$ & $81.80 \%$ & $11.70 \%$ \\
$\mathbf{1 9 2 0}$ & $1.20 \%$ & $6.20 \%$ & $1.90 \%$ & $69.10 \%$ & $21.60 \%$ \\
$\mathbf{1 9 2 7}$ & $0.20 \%$ & $7.00 \%$ & $0.80 \%$ & $89.20 \%$ & $2.80 \%$ \\
$\mathbf{1 9 4 4}$ & $0.17 \%$ & $1.78 \%$ & $0.61 \%$ & $83.97 \%$ & $13.47 \%$ \\
\hline
\end{tabular}

Fuente: Elaboración propia en base a los anuarios estadísticos y Menjivar (1980)

La dependencia de la economía salvadoreña hacia el café, se evidencia en el siguiente comentario del Ministro de Hacienda de principios de los años 30:

Cada vez que se produce la baja en los precios del café, automáticamente nuestra economía nacional entra en crisis, las actividades comerciales decaen, el valor de la propiedad disminuye, las operaciones de compra-venta de propiedad se paraliza, los bancos por razón de estatuto incierto, cortan los créditos y disminuyen la circulación monetaria y billetaria (sic), como consecuencia de todo esto, el fisco ve disminuir sus rentas (Arias, 1972: 86; Citado en Cáceres, 1986: 94)

En los años en que el café experimentó buenos precios, los beneficios derivados de estos no se restringieron solamente al sector cafetalero, sino que también se extendieron a otros grupos al interior de la sociedad salvadoreña como banqueros, exportadores, importa- 
dores e incluso el gobierno mismo. Las divisas generadas por las exportaciones de café financiaban el aparato del Estado y la construcción de la infraestructura que facilitó la comercialización de este cultivo (Cardoso y Pérez, 1977).

En cuanto al destino de las exportaciones, estas tuvieron como principales compradores a Estados Unidos y Europa Occidental, al menos hasta antes de la Segunda Guerra Mundial. Posteriormente Estados Unidos se convirtió en el principal socio comercial, Ilegando a comprar hasta un $80 \%$ de las exportaciones salvadoreñas para 1943.

Por otra parte, el escaso desarrollo de las demás ramas productivas nacionales exigió que las importaciones se compusieran de una gran variedad de productos fabricados, la mayoría de ellos destinados al consumo final.

Por ejemplo, la industria en general no registró mayor desarrollo a lo largo de todo el periodo. Muestra de ello es que para el año 1912 las importaciones de maquinaria agrícola y no agrícola solamente representaron el $4.2 \%$ del total de las importaciones, mientras que algunas importaciones que son insumos para labores agrícolas tales como sacos para café, abonos, alambre para cercas y ferretería, significaron conjuntamente un $12.91 \%$ del total de importaciones.

Los anuarios estadísticos preparados por la Dirección General de Estadística de El Salvador tampoco recolectaban información sobre esta rama de la actividad económica. A este respecto, en el anuario de 1932 se puede leer:

Hasta el momento, no se ha llevado en El Salvador ningún registro estadístico relacionado con la industria, debido a que esta rama de la actividad humana ha tenido anteriormente escasas manifestaciones por tratarse de un país esencialmente agrícola. Ahora que comienzan a tomar incremento ciertas actividades de naturaleza industrial, se están haciendo los estudios correspondientes para la apertura de los registros que darán la medida de la potencia industrial salvadoreña. (Anuario Estadístico de la República de El Salvador, 1932: 10)

Pese a los propósitos expresados no fue sino hasta el anuario de 1945 , después de la caída del régimen del
General Martínez, que se encuentra por primera vez una sección dedicada a la industria salvadoreña. 


\subsubsection{Estrategia económica}

Aunque el eje de acumulación de la economía salvadoreña durante este periodo fue indiscutiblemente el cultivo y exportación de café, la manera en que los gobiernos impulsaron este eje sí sufrió modificaciones. Se identifican dos periodos relevantes: de 1900 a 1930, donde la estrategia económica se caracterizó sobre todo por el liberalismo; y de 1932 a 1944, durante el mandato del General Martínez, caracterizado por un gobierno que participaba más activamente en la economía nacional.

\section{Periodo 1900-1930}

Para identificar la estrategia económica adoptada por el Estado salvadoreño en este periodo, se analiza principalmente el destino del gasto público a lo largo de esos años

En el año 1911 los gastos de represión ${ }^{1}$ representaron el $29.7 \%$ del gasto total, los gastos en educación el $6.9 \%$, y los gastos en capital físi$\mathrm{CO}^{2}$ el $45.5 \%$. Para 1929, los gastos en represión se habían reducido a $21.7 \%$, los gastos en educación incrementaron apenas a $8 \%$, mientras que los gastos en infraestructura alcanzaron el $52.3 \%$ del total.

Lo anterior muestra que durante ese período, los gobiernos tenían dos prioridades en cuanto al destino del gasto público: la construcción de infraestructura y las actividades represivas del aparato estatal.
Ambos elementos están vinculados con el funcionamiento del sistema productivo nacional, y sobre todo con la producción cafetalera ya que, por una lado, la dotación de infraestructura para el sector cafetalero por parte del Estado, agilizaba el comercio del café hacia el exterior, con lo que se potenciaba su desarrollo; y, por otro lado, el destino de recursos hacia los mecanismos represivos militares, aseguraban "el orden" y la "tranquilidad" que necesitaban los cafetaleros, en otras palabras, mantenían el status quo.

Esta adecuación del Estado salvadoreño a las necesidades del sector cafetalero, es explicada por el dominio directo que tenía la oligarquía cafetalera sobre el aparato estatal, en una medida tal, que la clase económica se confundía con la clase política en estos primeros años.

Por otra parte, hay que considerar que la producción cafetalera, en especial la de los pequeños agricultores, presentó algunas dificultades relacionadas con el sistema legal y de crédito vigentes, ya que el código civil permitía la permuta irrestricta de la propiedad, así como también el embargo de la propiedad hipotecada por incumplimiento.

Los beneficiadores asociados con los bancos concentraron la concesión de crédito a los pequeños productores y con esto se apro- 
piaron una buena parte de la producción de café. Con este proceso, a lo largo del período 1900-1930, la producción de café $y$, como fruto de ello, la posesión de tierra apta para su cultivo, se fue concentrando cada vez más, de manera que una minoría cafetalera se fortaleció y creó nexos con el capital bancario, lo que dejó en la deriva a muchos pequeños caficultores nacionales.

Así pues, la estrategia económica impulsada por los gobiernos durante el período 1900-1930, se caracterizó por tener como base un paradigma liberal, en el que los gobiernos minimizaban su participación sobre la actividad económica. Esta ausencia de Estado en materia económica, se tradujo en una desatención por parte de los gobiernos de la época hacia los pequeños y medianos productores de café, contribuyendo a que, a lo largo de este período, las tierras dedicadas a este cultivo se fuera concentrando.

\section{Periodo 1932-1944}

Durante el gobierno de Martínez, la estrategia económica hizo énfasis en apoyar a los productores de café. Además, la estrategia cambió de "intensidad", y la cantidad de medidas tomadas aumenta sustancialmente.

Las primeras medidas de política del gobierno de Martínez, enmarcadas en la crisis de los años 30, "fueron de carácter monetario y crediticio tendientes a impedir la quiebra de los productores de café, a mantener los ingresos del sector exportador -O aliviar su reduccióny dar al Estado la capacidad de control monetario del país" (Dada, 1978: 23). En este sentido encontramos:

- La creación del Banco Central de Reserva en 1934, con lo que los bancos comerciales pierden el derecho de emitir su propio papel moneda, y el control del circulante queda en manos del Banco Central de Reserva.

- La "ley de moratoria" de 1932 suspende la ejecución de hipotecas sobre la tierra.

- Ley que estipula la liquidación parcial de las deudas adquiridas por los caficultores, "lo cual favoreció especialmente a los pequeños cultivadores de café quienes habían contraído fuertes deudas en los años de prosperidad anteriores a la crisis" (White, 1987: 124).

- La devaluación de la moneda nacional, de un valor de $\$ 0.50$ a $\$ 0.4$.

- La creación de Banco Hipotecario para abordar el problema del crédito agrícola, cuya legislación apareciera en 1934 y cuyas operaciones inician en 1936.

Algunos años después, en 1942, se creó la Compañía Sal- 
vadoreña de Café, que se dedicó a la compra de café con el fin de estabilizar los precios, y también otorgó créditos de avío (Wallich et al., 1951: 201; citado en Parkman, 2006: 55).

Hay que mencionar además la prohibición del uso de maquinaria con motor para la fabricación de zapatos y de algunos otros artículos, "una concesión a las aspiraciones económicas de, al menos, un sector de los pobres" (White, 1983:124). Aunque indudablemente retrasaría el inicio del proceso de industrialización en El Salvador.

\subsubsection{Estructura laboral y modelo económico}

La población salvadoreña durante estos años se ubicaba sobre todo en el área rural, para 1930 el $61.7 \%$ de la población vivía en el área rural y el 38.3\% en el área urbana. Para 1944 el porcentaje de población rural había aumentado a $63.12 \%^{3}$

No obstante lo anterior, no hay elementos suficientes para afirmar que el modelo impulsó a las personas a esta zona, ya que la población salvadoreña ya era predominantemente rural y con ocupaciones eminentemente agrícolas antes de que este modelo se implementara en el país.

El mayor impacto en los movimientos de población se dio en el interior de la zona rural, ya que eran comunes los desplazamientos temporales de comunidades enteras hacia las áreas de cultivo de café, durante la época de mayor demanda de fuerza de trabajo. La temporalidad del desplazamiento responde justamente a una de las características de la demanda de fuerza de trabajo en el cultivo de café, puesto que necesita gran cantidad de fuerza de trabajo solo durante algunas épocas del año.

En la zona rural (y de hecho en todo el país) la ocupación remunerada más común era la de jornalero ${ }^{4}$, que representaba el $36 \%$ de la Población en Edad de Trabajar $\left(\mathrm{PET}^{5}\right)$. Los agricultores por su parte representan solamente el $2.6 \%$. Estos datos reflejan que las ocupaciones más numerosas están acordes a las necesidades de fuerza de trabajo de un modelo agro-exportador, y en específico con las necesidades de fuerza de trabajo asalariada que tiene la producción capitalista de café.

En las zonas urbanas las ocupaciones respondían más a las necesidades de bienes y servicios de la población de estas zonas, que a las necesidades de un eje de acumulación (como después lo harán con la industrialización). En este sentido, las ocupaciones se concentraban a un nivel de "oficios" como zapatero, albañil, carpintero, panadero, etc. El porcentaje de personas empleadas en este tipo de ocupaciones era igual al $8.5 \%$ de la PET. Las 
ocupaciones más comunes eran las de carpintero, costurera y zapatero.

En cuanto a las ocupaciones profesionales, estas tan sólo representaban un $0.64 \%$ de la PET. Entre aquellas profesiones que eran ejercidas por una mayor cantidad de personas, se encontraban profesores, que representan el $52.6 \%$ del total de profesionales; militares, $19.4 \%$; abogados, con un $6.9 \%$, y médicos con $5.16 \%$.

Al considerar la diferenciación por sexo aparecen datos interesantes. Las mujeres se ocupaban principalmente como profesoras, costureras, panaderas y en oficios domésticos. De hecho los oficios domésticos constituían una ocupación exclusivamente femenina en la cual se ocupaban el $94.7 \%$ de la PET femenina. Por el otro lado, los hombres se ocuparon en una mayor variedad de trabajos y fueron mayoría dentro de las ocupaciones profesionales (65\%). El trabajo de jornalero, que representa el $36 \%$ de la $\mathrm{PET}$, era declarado únicamente por hombres. Las razones de esta división se encuentran probablemente en los roles y los estereotipos asignados a las mujeres en el sistema de valores patriarcal ${ }^{6}$, las relegaban a ese tipo de profesiones

Así pues la mayoría de personas que se ocupaban en el cultivo y exportación de café (que representaba en ese entonces la mayor parte del sector capitalista de la economía) lo hacía en un empleo temporal como jornaleros, por lo que debían buscar la manera de sobrevivir durante las épocas del año en las que no había empleo. Dado el carácter mayoritariamente rural de la población, la agricultura de subsistencia fue la respuesta más común a esta necesidad

Este tipo de producción agrícola tenía entonces un papel relevante dentro de la estructura económica cafetalera, ya que cumplía dos objetivos muy importantes. Por una parte permitía que la fuerza de trabajo se reprodujera en aquellos meses del año, en que el sector cafetalero no les requería. Y, por otra, permitía a los cafetaleros pagar salarios bajos, por debajo del valor de la fuerza de trabajo, y así obtener una tasa ganancia elevada.

La permanencia de estas actividades fue posible en parte porque muchos campesinos conservaron sus propiedades agrícolas aun después de la extinción de las tierras comunales y ejidales, inclusive en zonas cafetaleras.

Por otra parte, en la zona urbana el capitalismo no se había consolidado todavía en la producción industrial; esto facilitó la existencia de productores artesanales que suplían las necesidades de bienes y servicios de la población urbana. Estos representan el $4.8 \%$ de la PET.

En lo que respecta a la educación, se puede decir que el eje de 
acumulación no requería de una fuerza de trabajo con altos niveles de instrucción. Por el contrario, la mayor parte de las actividades relacionadas con el cultivo del café necesitaban de una educación de lo más elemental (si no es que ninguna). El mantenimiento de una fuerza de trabajo fundamentalmente analfabeta fue posible gracias a la estrategia seguida por el gobierno de brindar poco apoyo a la educación, sobre todo en el área rural. Al respecto, Dana Munro dice:

La educación de las clases bajas ha sido intencionalmente limitada a algunos fundamentos, porque las autoridades han querido frenar la tendencia, tan perniciosa en toda Centroamérica, hacia la adopción de profesiones académicas a costa de los objetivos agrícolas (...) No existe ninguna ayuda del gobierno para los niños pobres que deseen proseguir estudios superiores ni en el país ni en el extranjero y más bien se hacen todos los esfuerzos posibles para alentar aquellos que han completado su educación primaria a que se incorporen al cultivo del suelo o al comercio. (Munro, 1918:110, citado en White, 1987:136)

Al revisar los datos de alfabetismo del censo de 1930, parece ser que estas intenciones se llevaron a cabo con bastante éxito, el $79.0 \%$ de la población era analfabeta, el $1.0 \%$ era semialfabeta ${ }^{7}$, y el $20 \%$ era alfabeta.

La educación media y superior, por su parte, era accesible únicamente a una pequeña parte de la población y refleja sobre todo las necesidades de profesionales de la población urbana.

En cuanto a los salarios, durante este periodo no hubo una legislación referente al salario mínimo, por lo que estos eran acordados mediante la negociación "libre" entre patronos y trabajadores. Esto condujo al pago de salarios muy bajos, lo que posibilitó a la clase capitalista obtener una plusvalía extraordinaria.

Si se comparan los salarios de algunos obreros urbanos para el año de 1925 con un presupuesto aproximado de la familia obrera en San Salvador equivalente a 97 colones $^{8}$ (Montoya, 1984), se tendría que las únicas ocupaciones que lograrían tener un salario capaz de cubrir las necesidades materiales de aquellos años, serían los caporales y los motoristas.

Para los trabajadores agrícolas, la situación salarial no estaba en mejores condiciones, tal y como se puede observar en las siguientes líneas escritas en la Revista Económica en 1924: 
$Y$ a pesar del margen enorme que realiza el finquero centroamericano, el jornal de los trabajadores de las plantaciones es el mismo mísero de siempre: 8 a 20 centavos oro (16 a 40 centavos de colón) endulzados con una puñada de frijol (citado por Montoya: 196, 1984)

Mantener este nivel de salarios fue posible gracias al excedente de fuerza de trabajo en la zona rural y a las ocupaciones no capitalistas que suplieron en gran medida las necesidades básicas de la población.

\subsection{Período 1948-1979: modelo agroexportador con impulso a la industria de la manufactura}

\subsubsection{Contextualización}

Este período histórico salvadoreño estuvo delimitado, tanto al inicio como al final, por la toma del poder mediante golpes de Estado. El primero del período pone fin a la presidencia del General Salvador Castaneda Castro y deja en el poder a una Junta Revolucionaria de Gobierno en 1948. Al final de este período, otro golpe de Estado acaba con el mandato del General Carlos Humberto Romero e instaura una nueva Junta Revolucionaria de Gobierno, en 1979.

El Estado asume un papel de "promotor del desarrollo" e interviene directamente en la economía. La industrialización encuentra cabida y se ve impulsada desde el poder del Estado, quien la presenta como sinónimo de desarrollo y modernidad.
Con ese discurso, entre otras cosas, logra adherir a la causa a amplios sectores de la población (incluyendo intelectuales); legitimar los incentivos dispuestos para el desarrollo de este sector e impulsa, además, un sentimiento de pertenencia y patriotismo mediante el consumo de bienes producidos por la industria nacional.

Entre los hechos más destacables en el ámbito internacional, se encuentran la crisis capitalista de 1973, que se origina en el alza en los precios del petróleo y que a su vez dejará sentir sus efectos sobre las economías periféricas por la vía del comercio internacional. El triunfo de la revolución cubana en 1959, ante lo cual EEUU busca promover la "democracia" expresada en una economía de mercado. $Y$, en América Latina, algunos países como Chile, México y Argentina se encaminaban hacia la concreción de un proceso incipiente de industrialización.

Finalmente, las dificultades económicas resultantes de las influencias tanto externas como internas, darán lugar a un período de efervescencia social y política, que posteriormente se convertirá en la guerra civil de El Salvador. 


\subsubsection{Modelo económico}

El modelo económico salvadoreño en el período previo a 1948, era el modelo agro-exportador basado en el café. Sin embargo, a partir de este año y a lo largo de este período, se operaron una serie de cambios muy importantes, que llevaron a pensar que nuevos ejes de acumulación habían hecho su aparición como importantes sectores de valorización del capital, y habían despojado al café de su casi exclusividad dentro de las exportaciones.

A pesar de ello, estos nuevos sectores no lograron desplazar al café como la principal fuente de divisas. Es más, el fortalecimiento de estos nuevos sectores (sobre todo de la industria) dependerá en gran medida de la robustez del sector agroexportador (principalmente el café).

\subsubsection{Eje de acumulación: nuevos sectores, mismo eje}

El algodón venía mostrando dinamismo desde la década de 1940 debido al incremento de la demanda local. Su mayor auge se dio en el primer quinquenio de 1960. Sólo en la década que va de 1950 a 1960, se duplicó su participación en exportaciones (de $7 \%$ a $13 \%$ ) y su participación respecto al producto agrícola ( $8 \%$ a $15 \%)$.

Pasado este boom, el algodón perdió importancia en las cuentas nacionales, sobre todo cuando se descubrieron los tejidos sintéticos y disminuyó la demanda de Japón, principal comprador de este producto.

Una característica de la producción de algodón era la concentración de la superficie y de la producción en grandes explotaciones ${ }^{9}$. Ello constituye una muestra del proceso de concentración de la tierra sucedido en el período.

La caña de azúcar tuvo cierto auge a raíz del bloqueo que impone EEUU al azúcar cubana. Su producción estaba distribuida más o menos homogéneamente entre las grandes explotaciones y las pequeñas, sin embargo muestra tendencia a concentrarse.

A pesar del mayor dinamismo de este sector, su participación en las cuentas nacionales no llega a ser muy significativa; tuvo su mayor participación respecto del Producto Territorial Bruto (PTB) a finales del período, en el año 1979, donde alcanzó un $1.1 \%$. En años anteriores, su participación fue bastante mínima; en ningún año supera un $4 \%$ del producto agrícola, y a nivel total no alcanza siquiera un $1 \%$.

El sector agrícola, como un todo, era el sector más importante de toda la producción nacional ya que en 1953 representaba el 35\% del PTB. No obstante, su importancia dentro del producto disminuyó sensiblemente durante las siguientes 
décadas y, para finales de 1970, su participación había disminuido hasta ser solamente $24 \%$. Aún así, la importancia del café como fuente de divisas era notoria. Para 1979, el $69 \%$ de divisas por exportación venían del sector agro exportador y, de estas, $63 \%$ se debían al café.

La industria manufacturera recibió gran impulso a través de incentivos y prestaciones que respondían a una estrategia económica diseñada para tal fin. Su participación en las cuentas nacionales incrementó vigorosamente en comparación con la presentada en períodos anteriores: en 1950 era $14 \%$ del PIB y en 1977 , $19 \%$. En solamente una década, de 1960 a inicios de 1970, la industria incrementa su participación en las exportaciones en 18 puntos porcentuales, pasando de un $4 \%$ a un $22 \%$. Se debe recalcar aquí el papel que en esto jugó el tratado de integración centroamericana, firmado en diciembre de 1960.

Sin embargo, pese al impulso recibido por la industria, el sector agrícola siguió gozando de la mayor parte del crédito, aunque este dato no se debe tomar a la ligera porque no era todo el sector agrícola el beneficiario, sino particularmente el sector agroexportador (el café y el algodón acapararon en promedio un $78 \%$ del crédito para este sector).

De esta manera, durante el período comprendido entre el inicio de la década de 1950 y la década de 1960, los sectores que más aportaban a la dinámica económica fueron el agrícola (por su peso sobre la producción) y el comercio (por su dinamismo). En la década comprendida entre 1960 y 1970, el sector más dinámico fue la industria manufacturera, aunque se debe enfatizar que, este dinamismo estuvo fuertemente influido por la estrategia económica. Finalmente, en la década comprendida entre 1970 y 1979 , se evidencia la pérdida de influencia del sector agrícola sobre el crecimiento de la economía, mientras el sector comercio acrecienta su importancia como propulsor del crecimiento, $y$, en menor escala (en relación con la década anterior), la industria manufacturera

El gráfico 1 muestra la contribución de diversos sectores a la tasa de crecimiento del PIB real. ${ }^{10}$

En definitiva, el impulso que los sectores daban al PIB, muestra que no pudo llegar a consolidarse a la industria como un eje de acumulación, a menos que se aceptara la hipótesis de la existencia de un eje de acumulación dominante (el agro-exportador) y uno subordinado (la industria). Además, se debe tener en cuenta que, ya desde finales de 1970, el comercio va mostrando una creciente importancia en términos de su participación en el PIB y de su crecimiento. 


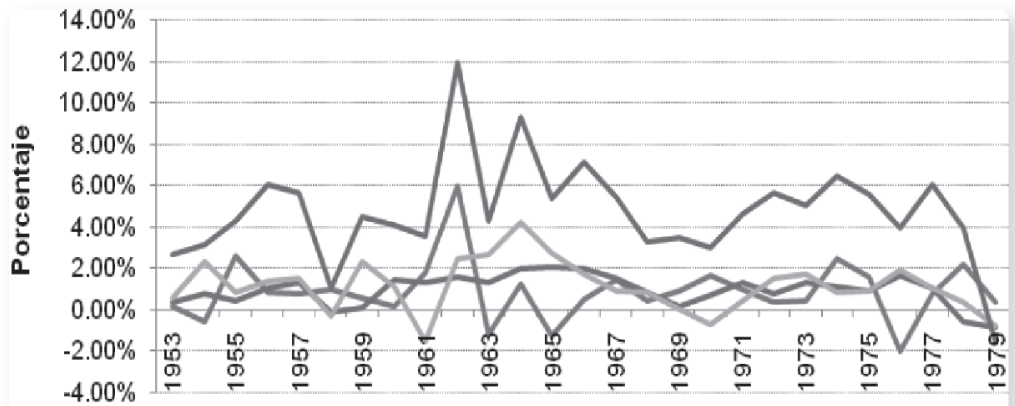

Años

- Agropecuario —Industria manufacturera —Comercio - PIB

Fuente: Elaboración propia, a partir de datos obtenidos en Castro (1984) y Lemus et al. (2007).

\subsubsection{Estrategia económica}

La industria se ve impulsada desde el Estado a través de una estrategia económica que, según Guidos et al. (1988), responde a la debilidad del grupo industrial tradicional y al desinterés de los grupos agro exportadores.

Un cambio emblemático lo constituyó el cambio en la constitución de la República en 1950. En ella se establecía un nuevo papel para el Estado y se creaba un marco institucional conveniente para su participación en búsqueda del desarrollo.

En materia fiscal, las medidas tomadas incluyeron la canalización de recursos desde el sector agroexportador hacia la naciente industria vía impuestos a la exportación (según Miranda et al., s.f., el $40 \%$ de los costos del café eran impuestos a la exportación); otorgamiento de incentivos fiscales (fomentando particularmente las sociedades anónimas) que implicó una gran transferencia de recursos públicos hacia el sector privado $y$, finalmente, la construcción de la infraestructura e institucionalidad necesarias para industrializar.

En relación con la política de ingreso, las condiciones salariales urbanas eran nominalmente menos desfavorables que las rurales. La exclusión de la fuerza laboral agrícola de las ventajas de una legislación laboral y la conmoción generada cuando el salario por fin se decreta en 1965 muestran que parte de la estrategia era, mantener 
la rentabilidad de los sectores agro exportadores, cuya estructura de costos promedio para la década de 1970, reflejaba un $42 \%$ de costos salariales (Miranda R. et al., s.f. ${ }^{11}$ y que, además, enfrentaba precios determinados en el mercado mundial.

La política crediticia, se caracterizó por un fortalecimiento de la institucionalidad, que buscó alentar a los bancos a hacer operaciones con menos tradición (crédito agroexportador) y/o a tantear campos menos explorados y hasta entonces no reglamentados (Industria y comercio).

Dos son las características más sobresalientes de la política comercial en este período: la del proteccionismo a la industria naciente, la del establecimiento de tratados comerciales bilaterales entre países centroamericanos $y$, finalmente, la integración de los mercados centroamericanos en diciembre de 1960.

Esta política es el instrumento que el Estado utiliza para superar una de las características antiindustrializantes (Dada, 1987) de la economía salvadoreña, a saber: la de poseer un mercado estrecho tanto por sus dimensiones como por el bajo poder adquisitivo de su población, derivado de una forma reproducción extravertida (la exportación de café) y de alta concentración de la riqueza (no solo ingreso, sino riqueza, que incluye la posesión de tierra, la cual es fundamental en una economía mayoritariamente agraria).
La iniciativa de la industrialización va a traer un cambio en cuanto a la composición de las exportaciones. Sin embargo, las relaciones comerciales de El Salvador con los países fuera de Centroamérica, no cambian de manera sustancial en este período: sus exportaciones siguen teniendo un componente fuertemente agrícola. Es más, la incipiente industrialización pone de manifiesto la dependencia de las importaciones de bienes intermedios y maquinaria de la economía salvadoreña ${ }^{12}$.

Además, la forma que asumió el modelo económico en El Salvador en este período, no solamente se vio afectado por las relaciones comerciales que este establecía con el exterior, sino que también lo afectó otro tipo de relaciones de carácter diplomático o económico, que vinculan de alguna manera a la FES salvadoreña con el exterior; mediante crédito, inversión y en muchos casos, derivado de lo anterior, mediante su influencia en la política económica.

Una de las influencias más importantes fue la de Estados Unidos de América (sobre todo con la Alianza para el Progreso). Un hecho bastante ilustrativo de esta influencia lo constituyó el que las características que adquirió el tratado de integración centroamericana (la de ser un tratado "librecambista", es decir, ampliador de mercados) estaban fuertemente vinculadas a 
los intereses que la burguesía salvadoreña (y también la guatemalteca) compartía, en gran medida, con los intereses estadounidenses ${ }^{13}$.

\subsubsection{Estructura laboral y modelo económico}

El período de la llamada industrialización en El Salvador modifica las características de la FES salvadoreña, pero no logra desplazar al sector agroexportador como el eje de acumulación principal de la economía, a pesar de que este empieza a perder importancia en la producción nacional hacia finales de la década de 1970

Por otra parte, de la población salvadoreña de este período el $60 \%$ era rural, aunque con tendencia a urbanizarse. Era en gran parte analfabeta, aún cuando en este período disminuye mucho el analfabetismo (de $60 \%$ en 1950 a $43 \%$ en 1971); y trabajaba en actividades agrícolas de subsistencia y de agro exportación que, aunque ocupaban al $60 \%$ de la toda la PEA, tendían a ser insuficientes como fuentes de empleo de una creciente fuerza de trabajo rural.

Así, la pérdida de importancia del sector agro-exportador, trasciende los indicadores de producción nacional y se extiende al ámbito del empleo. La PEA ubicada en esta rama tenía una participación mayoritaria pero descendente, y con un nivel de desocupación creciente.
Según DIGESTYC (1950), de cada cien personas desocupadas, dieciocho se ubicaban en la rama de agricultura. Para 1971, este número había ascendido a 54 personas.

Este escenario de desocupación, se unió a las dificultades para encontrar o tener acceso a tierras cultivables, e impulsó a la fuerza de trabajo a migrar masivamente a las ciudades, en especial San Salvador, cuya densidad poblacional se duplica en tan sólo una década (19501960). Debe recalcarse que este éxodo del campo a la ciudad se vio alentado también por la esperanza de encontrar un mejor futuro en la ciudad o sus alrededores, donde se había instalado casi el 90 por ciento de las nuevas industrias (La Prensa Gráfica, 1966).

No obstante, lo incipiente de la industria no le permitió dar ocupación a tantos brazos y, a pesar de que el sector construcción dio ocupación a una buena parte de esta fuerza de trabajo, el "exceso" de mano de obra rural que se mueve hacia la zona urbana, se irá consolidando como un "exceso" de mano de obra urbana, que se instala en condiciones de vivienda precaria (extendiéndose las zonas marginales, tugurios y vivienda informal) y que encuentra ocupación, más que en actividades industriales, en actividades impulsadas por la actividad industrial, sobre todo comercio y servicios (formal o informal). 
Es así como, a pesar de que la economía agrícola de subsistencia seguía siendo la forma económica no capitalista más extendida $(48 \%$ de autoempleo), la fuerza de trabajo no absorbida por las relaciones capitalistas (asalariadas) en la ciudad, buscó refugio en labores impulsadas a partir del dinamismo inyectado por la industria a toda la actividad económica urbana, como el comercio (donde un $59 \%$ era autoempleo) y los servicios. Se generan así las condiciones propicias para la expansión del que posteriormente será catalogado como el Sector Informal Urbano.
Otro aspecto relevante de la estrategia de impulso a la industria, lo constituye la reforma en el sistema educativo, ya que como parte de los requerimientos para industrializar, se hace necesario poner en marcha un plan que permita dotar a la fuerza de trabajo (al menos a las nuevas generaciones y una reducida parte de adultos) de los conocimientos necesarios para hacer viable este proyecto; conocimientos técnicos y administrativos, incluso a nivel de educación media:

\section{El bachillerato diversificado, fundamentalmente, intenta cubrir las necesidades de recursos humanos en los distintos campos del mercado laboral del país y su concepción y composición obedece a la urgencia de contar pronto con técnicos de nivel medio que promuevan, impulsen y en- riquezcan las diferentes áreas de producción. (Escamilla, 1981:163)}

Este es el objetivo con el que se diseña e implementa la reforma educativa de 1968 y con el que se crean diversas instituciones de educación técnica como el Instituto Técnico Industrial, entre otros.

La reforma educativa espera de sus universidades la formación de investigadores y la formación de técnicos de alto nivel. (Escamilla, 1981:143).

De esta manera, el cambio en el perfil educativo de la fuerza de trabajo se manifiesta en la mayor presencia de personas con formación técnica a nivel medio y universitario, donde en períodos pasados, eran los bachilleratos académicos y la medicina y la jurisprudencia las que atraían el mayor número de estudiantes. En otras palabras, no sólo se trató del ordenamiento del sistema educativo, sino de que las aspiraciones de la fuerza de trabajo en formación, pasaron primero por la decisión de qué conocimientos adquirir, en función de la posibilidad de cualificarse más y así, emplearse de mejor manera. 
Finalmente, debido a que el sector agroexportador siguió siendo el que impulsaba la economía nacional, la iniciativa gubernamental relacionada con el salario para trabajadores/as agrícola avanzaba muy lentamente y a veces retrocedió gracias a la influencia del capital de este sector. Así, las mejoras logradas para las personas trabajadoras agrícolas despertaban reacciones en su contra, mientras el establecimiento de salarios mínimos nominales superiores en otras ramas económicas, no fue particularmente objetado y/o impedido, ya que la alta rentabilidad en estos sectores (principalmente urbanos) se podía fundar en los incentivos fiscales $y$ otros beneficios otorgados como parte de la estrategia de impulso a la industria manufacturera.

En conclusión, las especificidades del modelo agro-exportador de este período y sobre todo la estrategia económica seguida para dar impulso a la industria, provocaron cambios importantes en la estructura laboral, de tal forma que las variaciones en dicha estructura respondieron a la estrategia económica y se correspondieron con las variaciones ocurridas a nivel de modelo económico, volviéndose un reflejo de la evolución de este último.

\subsection{9-1989. De la guerra a la paz: El período de transición desde el modelo agroexportador a uno terciario-maquilero}

Durante la década de 1980, el país se encontraba en un ambiente altamente conflictivo, caracterizado por la inestabilidad económica y tensiones políticas, situación que marcó el desarrollo de las estructuras económicas a lo largo de la década, y sentó las bases para la construcción de nuevos ejes económicos en décadas posteriores.

Con el derrocamiento del Gobierno del General Romero en 1979 , se puso de manifiesto la debilidad del Estado oligárquico, y a la par, el propio debilitamiento del modelo basado en la agroexportación (Segovia, 2002).

En esta época la estrategia gubernamental se basó, principalmente, en un esquema de alta intervención estatal y fuertes gastos públicos, especialmente aquellos destinados a apoyar el esfuerzo bélico en contra de las crecientes fuerzas armadas subversivas a los Gobiernos militares. La estrategia se repartió a lo largo de varios gobiernos, constituidos por juntas revolucionarias, y uno formalmente constituido por el Partido Demócrata Cristiano.

Bajo la conducción del Presidente Duarte, 1984-1989, y en medio de la guerra civil, la USAID presionó insistentemente por la implantación de medidas macroeconómicas que estabilizaran la situación económica del país, pero en su seno se trataba de políticas que, de 
alguna manera, buscaban acelerar el proceso de transición hacia una estructura de mercado funcional a los intereses del capital nacional e internacional (Barry, 1993).

Según Ayala et al., (2006) la estrategia económica que caracterizó los puntos básicos en este período puede explicarse a partir del anuncio de la primera Junta Revolucionaria, y contenía los siguientes elementos: (1) Establecimiento de bases firmes para la creación de un proceso de reforma agraria. (2) Reformas al sector financiero, tributario y de comercio exterior. (3) Protección al consumidor para contrarrestar la inflación. (4) Aumentar la producción mediante programas especiales de desarrollo. (5) Garantizar la propiedad privada en función social, derecho a la vivienda, educación y salud.

En 1980, bajo la conducción de la segunda Junta Revolucionaria, se buscó darle continuidad a los planes económicos impulsados por la junta anterior. Sin embargo, la fugacidad de su mandato no lo permitió, en cambio, se logró implementar una reforma en el carácter estructural de la tenencia de la tierra, altamente centralizado hasta entonces.

Posteriormente, durante los primeros años de la década, siguiendo la lógica de intervención estatal en la banca, la política crediticia se concentró principalmente, en el financiamiento preferencial al sector agropecuario. De igual modo se apoyó al sector construcción y a la industria manufacturera.

Con todo, para el momento en que la tercera Junta Revolucionaria estaba a punto de finalizar su mandato, y a las puertas de constituir un gobierno formal, se inició un plan de ajuste económico, de tal forma de hacer a El Salvador un país susceptible al crédito internacional (Schlageter, 1983).

La política fiscal se centró en reducir el déficit fiscal, tratando de eliminar o aminorar su incidencia negativa sobre la inflación y el déficit de la balanza de pagos. Para aumentar los ingresos, el gobierno utilizó impuestos indirectos (aumentó la recaudación fiscal). Así mismo se aumentó la tasa de impuesto de timbre fiscal de un $2 \%$ a un $4 \%$ y $5 \%$ para algunas transacciones de bienes y servicios. Adicionalmente se eliminaron algunos obstáculos a la importación de ciertos bienes para poder incrementar la recaudación proveniente de aranceles.

La política de ingresos estuvo encaminada a disminuir la inflación mediante una restricción en la demanda efectiva de los trabajadores asalariados. Se establecieron salarios mínimos para las diferentes ramas de la actividad económica. Aunque desde 1979 el salario en el sector agropecuario se mantuvo constante, con relación a los incrementos del sector servicios, 


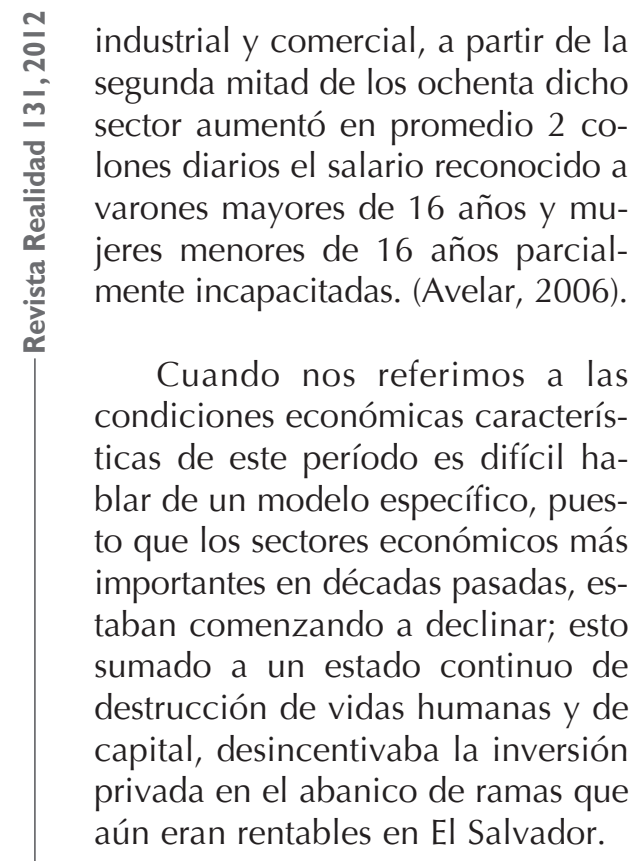

De esta manera es más apropiado referirse a este período como una etapa de transición histórica, en la cual el agotamiento progresivo del modelo económico anterior dió paso al nacimiento de nuevos ejes económicos, y con ellos, nuevas clases empresariales dominantes.

\subsection{Periodo 1989 - 2007: Modelo terciario-maquilero}

\subsubsection{Contextualización}

Durante el período reformista del presidente Duarte (19841989), el intento por reorganizar la agroindustria local y las fuertes intervenciones estatales se consideraron como la causa del malestar económico de ese entonces, por lo que la nueva administración pública en manos del reciente presidente electo Alfredo Cristiani, 1989-1994, buscó reorientar la economía nacional, basándose en una estrategia de crecimiento económico de corte neoliberal.

El contexto internacional cambió sustancialmente. Pese a la victoria obtenida por varias naciones opuestas al paradigma capitalista, en partes de Asia y América Latina, el mundo entero quedó conmocionado ante el derrumbamiento político y económico del bloque socialista soviético. Ello consolidó la política exterior de los Estados Unidos como un eje clave en el orden económico mundial dominante.

Las Instituciones Financieras Internacionales (IFI), que antaño fungieron como promotoras de la reconstrucción y el fomento de las economías devastadas por la Segunda Guerra Mundial, ahora servían a los intereses de acumulación del capital transnacional. Las economías subdesarrolladas, en especial las economías latinoamericanas, se planteaban una debacle en sus balanzas de pago ante la imposibilidad de cubrir la deuda externa obtenida en la década pasada, situación que las dejaba susceptibles a las plataformas de ayuda condicionada de las IFI, que buscaban agilizar los procesos de cambio hacia los nuevos ejes de acumulación transnacionales (Segovia, 2002). 
Las nuevas ideas de crecimiento y desarrollo económico, que vinieron a reemplazar la doctrina intervencionista, se perfilaron a base de una lógica económica concreta. Una lógica que se moldeó de acuerdo a las nuevas exigencias de valorización de capital, y que surgió a partir de los "Institutos de Investigación" y "tanques de pensamiento", de la denominada Mainstream economics, desarrollada principalmente en los Estados Unidos e Inglaterra (NSSR, 2008).

El triunfo de los Estados Unidos en la Guerra Fría significó el desenlace perfecto para las visiones económicas neoclásicas, tan acordes con la política exterior norteamericana; representaba pues, tanto una dimensión de prosperidad y crecimiento económico, como un poderoso componente ideológico, el cual asignaba una relación causal entre las libertades individuales de las personas y los pueblos, con la democracia, supuestamente inherente en la propia libertad de los mercados (Friedman, 1980).

En Centroamérica, los períodos de crisis y desequilibrios macroeconómicos en las décadas de 1980 y 1990, permitieron el desarrollo de los esquemas de ajuste económico de las IFI sobre las economías subdesarrolladas de la región.

Estos esquemas, que revistieron la forma de Programas de Ajuste Estructural (PAE) y Programas de Es- tabilización Económica (PEE), y que fueron el producto del autodenominado "Consenso de Washington" (Williamson, 2008), fueron la base material de los planes de estabilización y reactivación de las economías pobres de Centroamérica, estableciendo una serie de medidas estructurales que buscaron conciliar los objetivos de éstos con la realidad particular de cada país.

Los esquemas de reforma económica auspiciados por las IFI, mantuvieron una diferenciación en su modo de implementación, de acuerdo a la agenda programática de cada país y/o las características particulares de los mismos. Pese a lo anterior, el contenido de los programas se estructuró fundamentalmente en los siguientes puntos: asegurar la disciplina fiscal, establecer prioridades de gasto público, incrementar el gasto fiscal, liberalizar las tasas de interés y los flujos de inversión extranjera, privatizar empresas paraestatales para conseguir más eficiencia, disminuir las regulaciones para promover la competencia, garantizar los derechos de propiedad, entre otros.

\subsubsection{Modelo económico}

La estrategia de este período se caracteriza por una serie de medidas perfiladas en base a los PAE y PEE de las IFI, adoptadas por el gobierno de Alfredo Cristiani, y continuadas posteriormente por sus sucesores de derecha, para impulsar 
los cambios necesarios tanto a nivel de estructura económica, como de la FES salvadoreña.

El cambio en el modelo económico necesitaba de un esquema de cooperación estratégica entre el Gobierno y la empresa privada local e internacional (Paniagua, 2002), por lo que los lazos de entendimiento entre el Estado salvadoreño y las principales clases empresariales, previamente bloqueadas en el período del presidente Duarte, volvieron a ser determinantes en la consolidación del eje de acumulación de este período.

Esta nueva alianza entre los sectores privados y gubernamentales, y la puesta en marcha de los planes de privatización, permitieron un control sin barreras de los recursos estratégicos del país al capital nacional y transnacional (Paniagua, 2002).

En primer lugar, se eliminaron, de manera formal e informal, las dependencias que pudieran persistir hacia los antiguos ejes de acumulación. Para ello, se llevaron a cabo una serie de reformas que permitieron ampliar la órbita de valorización del capital privado, nacional y transnacional. Una forma que revistieron estas medidas fueron las políticas de liberalización económica pues con el propósito de hacer más eficiente el mercado nacional se optó por reducir sustancialmente la participación del Estado en la economía.
En este contexto, se inició una agenda de privatización de una cantidad razonable de activos, que se encontraban previamente en propiedad del Estado (Villalona, 2002). Este proceso de liberalización económica abarcó varios períodos presidenciales, teniendo su mayor auge en los primeros años de Gobierno de la década de 1990. (Segovia, 2002).

De igual modo se plantearon líneas de apoyo estratégico hacia sectores que pudiesen ayudar a consolidar un modelo económico que funcionara a partir de ramas productivas del sector terciario, así como exportaciones no tradicionales, promoviendo el crédito hacia esas ramas y generando las condiciones de una mayor apertura comercial.

Otro componente de la estrategia de este período se caracterizó por una reforma tributaria basada en la reorientación de la estructura de impuestos, disminuyendo la captación de ingresos por la vía directa y compensándolo con un aumento en impuestos indirectos, que afectaba más a los consumidores en relación con la clase empresarial (Segovia, 2002).

Debido a muchas de estas medidas, a partir de la década de los noventa se puede observar que la actividad económica se concentra, fundamentalmente, en tres sectores claves de la economía: el sector financiero, de comercios y el manufacturero-maquilas. 


\subsubsection{Ejes de acumulación}

Considerando la participación de los sectores más importantes de la economía salvadoreña desde el año 1990, claramente se puede observar que la industria manufacturera ha presentado una de las participaciones más determinantes en la última década y media: entre el 21 y $23 \%$ de la actividad del PTB; seguida de cerca por el Comercio y servicios que llega al $20 \%$. La agricultura, en cambio, año con año ve disminuida su participación del total de la producción de ser $17 \%$ en el año 1990, llega hasta un 13\% en 2007 (BCR, varias fechas).

Dentro de este modelo de libre mercado, adoptado por la administración del presidente Cristiani, existió la iniciativa de reemplazar el antiguo esquema de inserción al mercado mundial basado en la agro-exportación tradicional, por uno basado en las exportaciones no tradicionales que fuesen intensivas en mano de obra "barata". Los datos al respecto muestran claramente una reconfiguración en la estructura de exportaciones. Mientras que 1993 la exportación de productos del reino vegetal representaban cerca de un cuarto del total de las exportaciones, para 2007, el mismo rubro significaba un poco más del $6 \%$. Lo contrario ocurrió con las exportaciones de manufacturas, quienes pasaron de ser poco más del $28 \%$ de las exportaciones totales al $45 \%$ en el año 2007 (BCR, varias fechas)
Otra política que sirvió para configurar el modelo fue aquella referida al otorgamiento de créditos y apoyo financiero. Según los datos del BCR, los sectores que más se beneficiaron con la atención de los bancos al inicio de la década de los noventa, fueron el sector de comercio, la industria manufacturera y el agropecuario. Esta situación tendió a mantenerse en el caso de los dos primeros sectores, no obstante, el sector agropecuario quedó paulatinamente descuidado y parcialmente marginado de las políticas de incentivos a lo largo de esta década.

En la actualidad, el sector agropecuario se encuentra como uno de los sectores que menor captación de crédito se adjudica, precisamente por ser considerado como un sector improductivo y poco rentable.

Por último, según se aprecia en el siguiente gráfico, el crecimiento (decrecimiento) del PIB real ha tendido a ser cada vez menos influenciado por el crecimiento (decrecimiento) del sector agropecuario. Por el contrario, durante la década de 1990 la contribución de la industria manufacturera en el crecimiento del producto ha ido en ascenso; sin embargo, el comportamiento del producto refleja una relación igualmente importante con las fluctuaciones en el crecimiento de otros sectores como el de construcción, comercio y servicios. 
Así, el impulso que la industria, el comercio y los servicios han dado al crecimiento del PIB (y a la actividad económica en general), permite acuñar al modelo vigente como un modelo terciario-maquilero, en tanto los ejes de acumulación se encuentran en estos dos sectores productivos.

\section{Gráfico 2 \\ Tasa de crecimiento del PIB real y la contribución de algunos sectores}

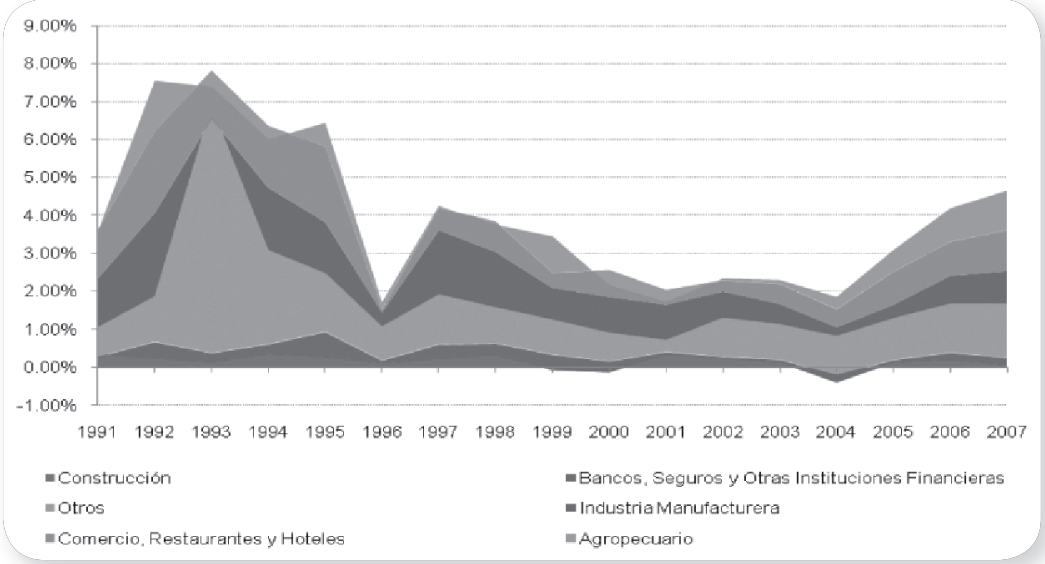

Fuente: Elaboración propia, a partir de datos de la revista mensual del Banco Central de Reserva, varios volúmenes.

\subsubsection{Estrategia económica}

Luego del fracaso de los planes interventores estatales, de la iniciativa cepalina por la industrialización centroamericana y ante el desastre económico y social causado por la guerra civil, el mando político y económico buscó dar respuesta a la gran pregunta sobre cuál debía ser el camino adecuado para El Salvador en la década de los noventa.

Gracias a la coordinación de recursos, y mediante la canalización de intereses públicos y privados, el
Gobierno, asistido por las propuestas técnicas de Fundación Salvadoreña para el Desarrollo Económico y Social (FUSADES), implementó un plan de desarrollo económico y social para operativizar su mandato. Por un lado, la apuesta del diseño estaba situada en un esquema de estabilización económica de corto plazo para hacer frente a la crisis económica, resabio de la década pasada; y por el otro estaba destinada a sentar las bases de una economía social de mercado de manera definitiva (Segovia: 2002). 
Según CENITEC (1991), las políticas económicas que se implementaron en este período se resumen de la siguiente manera:

- La política fiscal. Esta se encaminaba a la mejora de la eficiencia del sector público, con un mayor apoyo al sector privado y una disminución en su capacidad para intervenir en los mercados.

- La política de precios, bajo el esquema de libre mercado, se adecuó a la lógica de un sistema de mercado desregulado supuestamente eficiente; se buscó eliminar gradualmente los controles, tan comunes en la década anterior, hasta acabar finalmente con ellos. De este modo se pretendió que los precios reflejaran el valor real de los factores (incluido el factor trabajo, por supuesto) de los bienes y servicios.

- La política laboral de este período se planteó como una estrategia descrita, en parte, por la política de precios; de tal forma que se trató de que el empleo estuviera en función de la disponibilidad de la mano de obra en relación de los requerimientos específicos del capital. Es decir, la remuneración de la fuerza de trabajo sería una condición determinada por la pro- pia productividad del trabajo.

- La política monetaria y crediticia se puso en función directa de las necesidades específicas de la actividad considerada como productiva. Se utilizó al BCR como herramienta mediata de política, para garantizar la estabilidad macroeconómica, y la estabilidad en las áreas como: el financiamiento de actividades productivas donde exista capacidad ociosa y cuya inversión sea de rápida recuperación; la creación de grupos de financiamiento en aquellas nuevas actividades de exportación, y otras similares.

- La política comercial tuvo como objetivo garantizar una reforma a la naturaleza proteccionista del comercio exterior; que constituyó una apuesta para incentivar la exportación de bienes no tradicionales e intensivos en mano de obra de baja remuneración.

- Finalmente, la política cambiaria estaba encaminada a apoyar la estructuración de una estabilidad macroeconómica, basada en un ajuste realista y progresivo del tipo de cambio hacia el de las economías con las que se mantenían importantes lazos comerciales. 


\subsubsection{La estructura laboral y el modelo económico}

El periodo que va de 1989 a 2007 marca no sólo el inicio de una nueva era para la sociedad salvadoreña, sino el fin de los tradicionales paradigmas económicos. De frente al nuevo contexto económico mundial, El Salvador abandonó los viejos ejes de acumulación y se decantó por un esquema de crecimiento económico dependiente de la apertura comercial, el libre mercado y el uso de los bajos salarios como ventaja competitiva frente al mundo.

De esta manera, el deterioro del sector agrícola, como generador de divisas para la economía y fuente sostenible de empleos, fue una de las causas del proceso de migración de la PEA en este período, el cual comenzó a gestarse de manera continua en el período anterior, y estos terminaron por transformar el entorno del mercado laboral salvadoreño.

Según PNUD (2008), el dinamismo económico de la región metropolitana aporta un 58\% del PIB nacional, lo que evidencia una importante brecha de productividad entre las regiones rurales y urbanas del país. Esta asimetría en la productividad sectorial es normal, en tanto, los nuevos ejes del modelo, caracterizados por la presencia y evolución de los Sectores no Transables de la Economía y la Maquila, se ubicaron de manera sistemática $^{14}$ en las zonas urbanas del país. Así mismo, la demanda de más y mejores empleados/as, atrajo a la fuerza de trabajo que abandonó su tradicional modo de vida en el campo, optando en función de los requerimientos y demandas de los principales ejes del modelo.

Así, la fuerza de trabajo emigró desde las zonas rurales hacia donde pudiesen encontrar futuro a sus aspiraciones de empleo. Según DIGESTYC, la tendencia observable, en el período 1992-2005, muestra unos mayores niveles de "urbanización" poblacional; si bien en 1992 la población registraba una tendencia a distribuirse más o menos uniformemente (la población urbana llegaba al 50.44\%, mientras que la rural alcanzaba el $49.6 \%$ ), para 2005 más de la mitad de la población nacional se ubica en las zonas urbanas del país (el 62.65\%).

Si se observa la tendencia de ocupación de la fuerza de trabajo, podemos establecer su presencia en las zonas maquileras del país, la construcción, los servicios financieros, en los comercios, formales e informales, etc. Mientras que aquellas actividades relacionadas con la agricultura van decreciendo en importancia de ocupación.

Según DIGESTYC (1992), cerca de un $36 \%$ de la PEA total ocupada para 1991 se encontraba en la rama de Agricultura y otras relaciona- 
das, frente a un $25 \%$ a finales de esa misma década, y un $19 \%$ para 2006. Los sectores de manufacturas y comercio han tenido, no obstante, incrementos sensibles a lo largo de la década. La rama de comercio partió de un $17 \%$ en 1991 hacia un $25 \%$ en 1998 , y un $30 \%$ para 2006. El sector de manufacturas parte de un $17 \%$ en 1991 hasta un $19 \%$ en el año 1998, y un $16 \%$ en 2006.

Sin embargo, a medida que las exigencias de la fuerza de trabajo por más y mejores opciones de empleo aumentaron, se hizo cada vez más claro que las propias capacidades inherentes a este modelo para generar fuentes de empleo tenían límites muy ajustados, característica compartida con los modelos económicos anteriores.

Al concentrar una gran dependencia en el uso de mano de obra de baja remuneración para las actividades de maquila y el uso reducido de mano de obra calificada en el comercio y servicios, los ejes que sostenían al modelo no han sido capaces de generar suficiente empleo para toda la población. Así, la presencia de una sobrepoblación relativa a las exigencias del capital ha venido creciendo hasta consolidarse en vastos sectores de fuerza de trabajo auto empleada o subempleada. A modo de ejemplo, según PRISMA (2001), las actividades del sector informal se concentraron fuertemente en el comercio, donde representan casi el $75 \%$ del empleo en ese sector y la mitad del empleo en el sector urbano informal.

Estos sectores de autoempleo, caracterizados por la informalidad, se encuentran tanto en la zona urbana como en la rural $y$, dada su presencia significativa en ambas zonas, se puede confirmar que, al igual que los modelos anteriores, estas se corresponde con una incapacidad estructural para responder las propias demandas del mercado laboral a través del desarrollo de formas capitalistas de producción. Según DIGESTYC (1998), cerca del 44\% del total de los ocupados lo estaban en condiciones de autoempleo, o empleo por cuenta propia, en la zona rural. De ellos, la gran mayoría $(74 \%)$ laboraba sin un local propio, es decir, de manera ambulante o en sus hogares.

Se debe mencionar que, si bien es cierto que la presencia de estas formas es común a las zonas rural y urbana, dicha presencia no tiene una importancia homogénea. Se descubre que existe una tendencia mayor a que existan formas no capitalistas en las zonas rurales relacionadas directamente con la propia sobrevivencia de las personas, mientras que en la zona urbana se trata de esta misma generalidad acompañada de una relación con los propios asalariados. De esta manera se cumplen las condiciones de permitir, no sólo la propia sobrevivencia, sino ayudar en la reproducción a bajo costo de la fuerza de trabajo asalariada. 
Se hace necesario indicar que, para impulsar los nuevos ejes, la lógica interna del modelo requería que las autoridades nacionales generaran las condiciones básicas para una capacitación más elaborada a la fuerza de trabajo, por ello se pusieron en marcha una serie de reformas al sistema educativo a lo largo de la década del noventa, con el propósito de lograr la mejor capacitación de las nuevas generaciones a emplearse en los polos considerados de crecimiento. Desde el período del conflicto armado hasta la fecha, los esfuerzos en materia educativa se vieron focalizados por un plan estratégico de estudios y diagnósticos sobre el sistema de educación nacional, que eventualmente conllevarían a la reforma global de educación (MINED, 1995). La ampliación de la cobertura educativa de 1991 a 2007 ha tenido avances significativos: la tasa bruta de matrícula en parvularia se incrementó de 21 a $51 \%$ y la tasa neta de matrícula en la educación básica ha crecido de $21 \%$ a un $96.4 \%$ (FUSADES, 2008).

Pese a los logros en materia educativa, las necesidades de acumulación de cada eje no son igualmente compartidas en términos de capacitación laboral. Las ramas como servicios o comercio requieren fuerza laboral de alta capacitación, con relación a otras ramas como la maquila, que concentra grandes cantidades de asalariados/ as con poca cualificación.
Los datos nos muestran que la educación de la PEA es baja con relación al resto de Latinoamérica; y que si bien es cierto que las nuevas generaciones están mayormente capacitadas que sus padres, existe un serio desbalance en la capacitación de la fuerza de trabajo en la zona urbana y rural, estando la población rural en una situación de rezago educativo en donde no predominan sectores que demanden una población con alta o media calificación en su trabajo. (FUSADES, 2002).

De hecho, una de las estrategias básicas que se siguió para la reconfiguración del sector rural durante éste período, se concentró en la explotación de una fuerza de trabajo en actividades intensivas en fuerza laboral de baja cualificación.

La reconfiguración progresiva de los currículos de enseñanza es un reflejo claro de las exigencias del modelo mediante el mercado laboral, hacia las instituciones superiores de enseñanza. Según MINED (2007), en los últimos años, del total de carreras registradas como opciones de educación superior, la mayor demanda de la población estudiantil matriculada se encontraba en las ramas de economía, administración y comercio (32\%); tecnología ${ }^{15}(22 \%)$; salud $(19 \%)$ y derecho $(14 \%)$.

Sin embargo, la menor demanda se encuentra en carreras como ciencias puras (2\%); agricultura y medio ambiente (1\%). Esta deman- 
da y oferta de calificación especializada responde a una lógica particular que enmarca a la educación superior en la realidad del mercado de trabajo.

El mercado de trabajo nacional, no obstante, responde en su dinámica interna a la propia dinámica del modelo de acumulación, y en esta medida, a los ejes y sus necesidades de fuerza laboral. En este sentido, son pocos los puestos de trabajo que estimulen la presencia de carreras universitarias volcadas hacia la investigación científica o el estudio de los procesos sociales "per se", en cambio, se observa una instrumentalización de los principios institucionales de la revolución de 1968, la cuál se ve reflejada en la alta demanda de carreras técnicas o administrativas, de medio o bajo perfil investigativo. (Fernández y Carrasco, 2000)

Si bien, como lo establece Aguilar A. (1995), las distintas reformas al sistema educativo nacional, ocurridas en el período estudiado, se muestran como dentro de las más exitosas en su calidad técnica y administrativa, las mismas no incorporan un elemento vinculante entre los requerimientos científicos del crecimiento y desarrollo económico con la propia realidad nacional. Se trata más bien, de un mejoramiento y expansión de la estrategia educativa que se había venido gestando en el país en períodos anteriores, y por tanto, se trata de una réplica más o menos constante de los procesos que contribuyeron al subdesarrollo en el pasado.

Por otra parte, la lógica de remuneración se ha consolidado de tal forma que los recursos que el trabajador perciba no obstaculicen la lógica de acumulación del capital.

Si se revisa la historia de la década de los noventa se puede observar que las variaciones en el salario mínimo han sido escasas, de hecho, la mayoría de estas han respondido a movimientos de precios en la canasta básica, indicador que recoge los rubros mínimos de sobrevivencia la cual, según las autoridades gubernamentales, corresponden al asalariado de la ciudad y el campo. ${ }^{16}$ De hecho, la relación entre salario mínimo nominal (industrial) y la canasta básica urbana nos muestra variaciones positivas pero muy modestas, entre uno o dos puntos porcentuales, a lo largo de la última década.

Por otro lado, existen diferencias considerables entre los salarios promedio y los salarios mínimos de las distintas ramas. Es de esperar que aquellos ubicados en las ramas o actividades de la economía de la zona urbana gocen de una mayor remuneración. (PNUD, 2008)

Según PNUD (2008), la tendencia misma de los salarios mantiene una dirección opuesta a la propia 
productividad del trabajo. Mientras que esta última ha tendido de manera histórica a subir, la primera ha mostrado una tendencia a la baja.

Ese tipo de prácticas de desvalorización de la fuerza de trabajo son posibles gracias a la intervención de otras estructuras ajenas al propio modelo de acumulación, pero sin las cuales este no podría desplegar su máximo potencial. Algunos ejemplos de esto son los trabajos de reproducción de la fuerza de trabajo bajo formas económicas no capitalistas volcadas principalmente a la ocupación por cuenta propia en el sector informal del comercio, y la intervención del componente de remesas como complemento al ingreso familiar.

Es por ello que el proceso de reacumulación primaria de capital, experimentado en los inicios de la década de los noventa, mantuvo una cercana relación con los elementos estudiados de la estructura laboral, desde las estructuras institucionales hasta los procesos migratorios de la población. La estructura laboral ha tenido una evolución marcada por el desarrollo, auge y crisis de los procesos capitalistas en El Salvador.

\section{Conclusiones}

Estos tres modelos económicos y las estrategias con que se ha impulsado a determinados sectores productivos en El Salvador han estimulado la movilización de la fuerza de trabajo. Esta movilización se ha dado en tres sentidos: una movilización cualitativa, que se manifiesta en el cambio en el perfil educativo de la fuerza de trabajo en respuesta a las necesidades del eje o los ejes de acumulación; una movilización geográfica que hace referencia a las concentraciones de población en las zonas económicamente más dinámicas (incluyendo otros países) y una movilización de un sector productivo a otro, que hace alusión al traslado desde actividades rurales (agrícolas) hacia actividades urbanas (industriales, de comercio y servicios).
Ahora bien, históricamente los sectores productivos capitalistas, aún los más dinámicos, no han logrado absorber la totalidad de la fuerza de trabajo disponible. Esta incapacidad, inherente a la economía capitalista salvadoreña, ha hecho necesario que la fuerza de trabajo busque garantizar su sobrevivencia ocupándose en actividades económicas no capitalistas, que se desarrollan en los alrededores de las zonas cuya actividad económica se ve impulsada por estos sectores más dinámicos.

La naturaleza de estas actividades se vincula a las necesidades específicas de explotación de fuerza de trabajo de los ejes de acumulación de cada periodo, y permanecen y se extienden en la 
medida que hacen posible una mayor velocidad de rotación del capital mercancía. A través del comercio no capitalista, le "ahorran" al capital el tener que desembolsar de sus propios fondos para mantener viva la fuerza de trabajo que requiere, a través de producción de valores de uso, y le proveen de mercancías que paga por debajo de su valor mediante su relación con la producción mercantil simple. De esta manera, el capital subsume indirectamente estas actividades, volviéndolas un instrumento más de su proceso de valorización.

A esta valorización extraordinaria derivada de la expoliación de los sectores no capitalistas, se suma otra no menos significativa, que también es posible por la existencia de estos sectores y es la que resulta de la sobreexplotación de la fuerza de trabajo.

A lo largo de la historia, el capital en El Salvador ha visto en esta sobreexplotación una fuente segura y oficialmente permitida de competitividad y rentabilidad, debido, entre otras cosas, a que los salarios mínimos han funcionado eminentemente como una estrategia de impulso a los sectores que son, o se quiere que sean, los ejes de acumulación. Esto ha posibilitado que pase a un segundo plano el desarrollo de mejoras tecnológicas y con ello se frene la productividad del trabajo.
Esta particularidad del comportamiento del capital puede ser presentado como un problema circular: la sobreexplotación frena el desarrollo tecnológico; este a su vez genera que la productividad se mantenga baja $y$, finalmente, esta baja productividad es el argumento de la existencia de bajos salarios (de salarios de sobreexplotación).

Visto de esta manera, parecería que es posible romper con ese círculo mediante un incremento en la productividad. Sin embargo, estudios recientes ${ }^{17}$ han mostrado que, pese a que la productividad del trabajo en El Salvador ha incrementado en los últimos años, los salarios reales de la población se han deteriorado. Con ello se evidencia cómo los incrementos en la productividad junto con la sobreexplotación (y no en lugar de esta) son las fuentes de la rentabilidad del capital en El Salvador.

De este modo, las características socio-económicas de la fuerza de trabajo salvadoreña, es decir, las que dependen directamente o indirectamente del salario o los ingresos ${ }^{18}$ que esta perciba, quedan explicadas parcialmente por el patrón de acumulación ${ }^{19}$ de los distintos modelos económicos.

Finalmente, la relación de la estructura laboral de El Salvador con los modelos económicos ha mostrado que la fuerza de trabajo 
es un elemento esencial del sistema productivo, ya que las características de la fuerza de trabajo experimentan modificaciones que responden a la estrategia económica y que reflejan los cambios que se van sucediendo a nivel de modelo económico.

\section{Bibliografía}

(S/A) (1924-1927) Revista Económica. San Salvador

Aguilar A., (1995) Un vistazo al pasado de la educación en El Salvador. Reforma Educativa en Marcha, Documento I, San Salvador, Ministerio de Educación.

Aguilar A. (1995), Un vistazo al pasado de la educación en El Salvador. Reforma Educativa en Marcha, Documento II: Consulta 95", San Salvador, Ministerio de Educación.

Banco Central de Reserva. Revista Mensual. Varios Años

Barry, D., (1993) Una herencia de AID en El Salvador: andamiaje institucional empresarial en la sociedad civil. San Salvador, Programa Salvadoreño de Investigación sobre el Desarrollo y Medio Ambiente (PRISMA).

Browning, D. (1975) El Salvador, la tierra y el hombre. Primera edición en español. San Salvador. Dirección de Publicaciones del Ministerio de Educación
Centro de Investigaciones Tecnológicas y Científicas. Dirección de Investigaciones Económicas y Sociales. (1991) Política económica y pobreza rural, San Salvador, CENITEC.

Cuéllar Marchelli, Helga, (2007) Evaluación del financiamiento público para la educación. San Salvador, FUSADES.

Dada Hirezi, H., (1987). La economía de El Salvador y la integración centroamericana 1945-1960. Quinta edición. UCA editores. San Salvador, EI Salvador.

Dirección General de Estadísticas y Censos (DIGESTYC). Anuario estadístico, varios años.

Dirección General de Estadísticas y Censos (DIGESTYC, 1930), Censo del $1^{\circ}$ de mayo de 1930. San Salvador, El Salvador.

Dirección General de Estadísticas y Censos (DIGESTYC, 1950). Segundo Censo Nacional de Población, 1950. 
Dirección General de Estadísticas y Censos, (1992) Quinto Censo Nacional de Población. San Salvador, DIGESTYC.

Dirección General de Estadísticas

y Censos, (2007) Sexto Censo Nacional de Población. San Salvador, DIGESTYC.

Dirección General de Estadísticas y Censos. (Varios años) Encuesta de Hogares de Propósitos Múltiples (Varios volúmenes), San Salvador, DIGESTYC-MINEC.

Escamilla, L. (1981). Reformas educativas. Historia contemporánea de la educación formal en El Salvador. Dirección de publicaciones, Ministerio de Educación. El Salvador, 1981.

Friedman, M; R., (1980), Libertad de elegir: hacia un nuevo liberalismo económico. Barcelona, Grijalbo-Mondadori.

Fundación Salvadoreña para el Desarrollo Social y Económico, (1989) Hacia una economía de mercado en El Salvador: bases para una nueva estrategia de desarrollo económico y social, 1989-1994. San Salvador, FUSADES.

Fundación Salvadoreña para el Desarrollo Social y Económico, (2008) Democracia y crecimiento: fundamentos del desarrollo, 2009-2014. San Salvador, FUSADES.

Fundación Salvadoreña para el Desarrollo Social y Económico. (1994) El Salvador, estrategia 94-99: Solución social y reformas económicas. San Salvador, FUSADES.

Gerencia de evaluaciones e información estadística. MINED. (2007) Ecuación Superior en Cifras, El Salvador. 1997-2006. San Salvador, Ministerio de Educación.

Guidos, R., (1988). El ascenso del militarismo en El Salvador. Cuarta edición. UCA editores, San Salvador.

Guidos, R., Cáceres J. y Menjívar R., (1988). El Salvador: una historia sin lecciones. Ediciones FLACSO. Costa Rica.

Lindo, H. (2002) La economía de EI Salvador en el siglo XIX. Dirección de Publicaciones e Impresos, San Salvador.

Martínez, J., Perfil de género de la economía salvadoreña: documento de trabajo (2006), UNIFEM. San Salvador, El Salvador.

Montoya, A. (1984). "Antes del 32". Publicado en Boletín de Ciencias Económicas y Sociales. 
Montoya, A., (1998) Economía crítica, San Salvador, Editores Críticos.

Paniagua, C., (2002), "El bloque empresarial hegemónico salvadoreño". San Salvador, ECA, números 645-646., UCA Editores.

Parkman, P., (2007) Insurrección no ciolenta en El Salvador: La caída de Maximiliano Hernández Martínez, San Salvador, Dirección de Publicaciones e Impresos

PNUD (2008). Informe sobre Desarrollo Humano El Salvador 2007-2008. El empleo en uno de los pueblos más trabajadores del mundo. San Salvador. Programa de las Naciones Unidas para el Desarrollo.

Segovia A., (2002), Transformación estructural y reforma económica en El Salvador: el funcionamiento económico de los noventa y sus efectos sobre el crecimiento, la pobreza y la distribución del ingreso, Guatemala, F\&G Editores
The New School for Social Research (2008). "The Marginalist Revolution of 1871-74, Introduction to the Neoclassicals". [En línea]. Disponible en: http://cepa. newschool.edu/ het/essays/ margrev/ncintro.htm [Accesado en agosto de 2008]

Villalona, C., (2002) "Programa de Ajuste Estructural en Centro de Investigaciones Económicas y Políticas de Acción Comunitaria, CIEPAC. [En línea]. Chiapas, México. Disponible en: http://www.ciepac.org/archivo/ analysis/ajuste.htm [Accesado en agosto de 2008]

White, A. (1983) El Salvador. San Salvador. UCA Editores.

Wilson, E., (2004) La crisis de la integración nacional en EI Salvador 1919-1935, Primera edición, CONCULTURA.

Williamson, John. "Una historia corta sobre el Consenso de Washington/A Short History of the Washington Consensus" Instituto para la Economía Internacional. [En línea] www.iie. com/publications/papers/www. iie.com/publications/papers/ williamson0904-2.pdf 
1. Guidos (1980) denomina a los gastos realizados en Guerra, Marina, Aviación y Justicia para 1911 y 1929, gastos de "represión".

2. Este tipo de gasto implica aquellos egresos que no pueden aportar los capitales privados, dada la naturaleza riesgosa y de largo plazo de algunas inversiones. Dentro de estos gastos estaban aquellos dedicados al mejoramiento de las obras públicas, construcción de caminos y carreteras, puertos, etc. También se incluye en este rubro el pago de servicios de deuda pública contratada para la construcción de infraestructura

3. Estas cifras no dan cuenta de las migraciones internas, debido a que la Dirección General de Estadísticas calculaba el incremento poblacional sumando a la población la diferencia entre los nacimientos y las defunciones registradas.

4. Jornalero/a es una persona que vende su fuerza de trabajo de manera temporal, recibiendo un pago por cada día de trabajo.

5. Con base en el censo de 1930 se puede clasificar a la población en edad de trabajar (PET) considerando a la población mayor de 15 años. En base a ese criterio, se tendría que la PET para 1930 sería de 857,499 personas y representa el $59.7 \%$ de la población total

6. Cf. Martínez (2006: 6-7).

7. El término semialfabeto se refiere a las personas que solamente pueden leer, mas no escribir (DIGESTYC, 1930)

8. Este presupuesto fue realizado por la Revista económica para los años 1925-1926. Dentro de este, se consideraba que los gastos en alimentación representaban el 51.5\%, el gasto en vestido el $15.5 \%$, en vivienda $20.6 \%$, mientras que salud, transporte, etc., en $12.4 \%$.

9. Cf. Barrera et al. (2008: 55)

10. Esta contribución fue calculada a partir de la fórmula:

Donde:

tc $P I B=$ tasa de crecimiento del PIB real en el año " $t$ ".

$=$ Proporción que cada sector representa respecto al PIB en el año " $t-1$ "

$=$ Tasa de crecimiento del sector "i" respecto a su valor en el año " $t-1$ "

11. Asumimos que una o dos décadas antes (1950-1960) la estructura de costos era similar a la presentada en la década de 1970.

12. Cf. Barrera et al. (2008: 140)

13. Para ampliaciones respecto a la integración centroamericana consultar: Dada, H. (1987)

14. Según el Plan de Desarrollo Económico y Social 1989-1994 (MIPLAN,1990) y el plan País Seguro (ARENA, 2004), la apertura y promoción de maquilas en el territorio nacional no contenía como punto central el acceso de éstas fábricas a la población de la zona urbana, o rural, de manera preferencial y con líneas estratégicas de desarrollo sectorial; en cambio, era un punto de honor el generar las condiciones propicias en materia legal y de infraestructura para que pudieran rápidamente emplear a una fuerza de trabajo de baja cualificación y que, al mismo tiempo, les acercara a los nodos lo- 
gísticos, de mar y tierra, para la fácil exportación de su productos.

15. Es necesario aclarar que, aunque se hable de la carrera de "tecnología" de manera genérica, en rigor se hace referencia mayoritariamente a carreras como la ingeniería civil, industrial o de sistemas. Además, se hace referencia a los técnicos relacionados con el mantenimiento de sistemas informáticos o computadoras.
16. Cf. Barrera et al. (2008: 108-109)

17. Cf. PNUD (2008)

18. Para el sector no capitalista y/o salario incluyendo remesas.

19. Esto hace referencia a la manera en que se acumula. En el caso de El Salvador, el patrón de acumulación es la sobreexplotación. 